\title{
Physical and Mechanical Properties of Graphene Nanoplatelet-Reinforced Al6061-T6 Composites Processed by Spark Plasma Sintering
}

\author{
MAHMOOD KHAN (1), ${ }^{1,4,5,6}$ RAFI UD-DIN, ${ }^{2,7}$ ABDUL WADOOD, ${ }^{1,8}$ \\ SYED WILAYAT HUSAIN, ${ }^{1,9}$ SHAHID AKHTAR, ${ }^{3,10}$ \\ and RAGNHILD ELIZABETH AUNE ${ }^{4,11}$ \\ 1.-Department of Materials Science and Engineering, Institute of Space Technology, \\ Islamabad 44000, Pakistan. 2.-Materials Division, Pakistan Institute of Nuclear Science and \\ Technology, Nilore 45650, Pakistan. 3.-Norsk Hydro, Karmøy Primary Production, Hydrovegen, \\ 4265 Håvik, Norway. 4.-Department of Materials Science and Engineering, Faculty of \\ Natural Sciences, Norwegian University of Science and Technology, 7491 Trondheim, \\ Norway. 5.-e-mail: mahmood.khan@ntnu.no. 6.-e-mail: mahmoodkhan77@gmail.com. \\ 7.—e-mail: rafi_682@hotmail.com. 8.—e-mail: abdul.wadood@mail.ist.edu.pk.99.—e-mail: \\ wilayat.hussain@ist.edu.pk. 10.—e-mail: shahid.akhtar@hydro.com. 11.—e-mail:
} ragnhild.aune@ntnu.no

\begin{abstract}
Aluminium matrix composites with high specific strength are attracting attention for use in automobile and aerospace applications. Graphene nanoplatelets (GNPs) were added in 0.1, 0.5, and 1 weight fractions to an Al6061 matrix. Spark plasma sintering was used with a combination of solution sonication and ball milling to disperse the GNPs in the Al6061 matrix. The evolution of the microstructure was studied using optical and scanning electron microscopy. The uniformity of the GNP distribution is discussed in light of selected ball milling parameters. Electron backscattered diffraction analysis was used to measure the grain size and misorientation. X-ray diffraction analysis and transmission electron microscopy revealed neat and clean interfaces between the matrix and GNPs. Hardness and tensile testing revealed a considerable increment in the strength of the final composite after addition of GNPs. Traces of GNP clusters were found in the 1 wt.\% composite as well as premature failure at lower strain due to the insufficient load transfer capability of the Al6061-T6 matrix. An illustrative two-dimensional model was developed to explain the load transfer behavior and the deterioration of the mechanical properties.
\end{abstract}

\section{INTRODUCTION}

Aluminum and its alloys are essential materials for domestic and industrial applications. ${ }^{1}$ Developments in the field of high-performance materials are of increasing importance. ${ }^{2}$ Aluminum matrix composites (AMCs) containing lighter reinforcements are amongst the established and proven composites for use in specialized applications. ${ }^{3}$ Among emerging lightweight nanoreinforcements, graphene is leading the race due to its exceptional properties in terms of stiffness and high thermal and electrical conductivity. ${ }^{4}$ GNPs have been added to aluminum at different weight fractions (wt.\%) to develop
aluminum/GNP composites (Al-GNPs). The advantage of including GNPs in an aluminum matrix is their direct interaction with dislocations. ${ }^{5}$ Besides the above-mentioned advantages of graphene, GNPs are light weight with extremely high surface area (approximately 10 times greater than carbon nanotubes $\left.(\mathrm{CNTs})^{6}\right)$ and possess excellent loadbearing capacity. ${ }^{7}$ These properties enhance the mechanical properties of AMCs. ${ }^{8}$ Addition of GNPs to AMCs affects the strengthening mechanism via: (1) load transfer from the matrix to reinforcement, ${ }^{9}$ (2) pinning of dislocations, ${ }^{10}$ and (3) grain refinement (studied herein). GNPs have become a favorable choice for nanoreinforcement due to their 
unique two-dimensional structure, which allows them to act as a crack barrier and leads to deflection and bridge effects that greatly enhance the toughness of the Al6061 matrix..$^{11}$ However, the nonwetting nature of the surface of GNPs has always resulted in severe issues with their dispersion in an aluminum matrix. ${ }^{12}$

Achieving a uniform dispersion of GNPs in the aluminum matrix is vital in order to translate the superior properties of GNPs to Al-GNPs composites. ${ }^{13}$ Traditional AMC processing techniques, such as stir casting, cannot overcome the problem of clustering of nanoreinforcements. ${ }^{14}$ Various other processing techniques have been developed to produce Al-GNPs, e.g., liquid infiltration, ${ }^{15}$ powder metallurgy ${ }_{18}^{16}$ friction stir processing, ${ }^{17}$ extrusion, hot rolling, ${ }^{18}$ and spark plasma sintering (SPS). ${ }^{19}$ Powder metallurgy is unique amongst all the processing routes for Al-GNP composites, ${ }^{20}$ due to (a) its being a solid-state processing method and (b) its comparatively lower processing temperatures. Powder processing and associated ball milling allow sufficient dispersion and minimal agglomeration of the nanoreinforcement. ${ }^{21}$ Conventional powder metallurgy ends with sintering into the final shape. ${ }^{22}$ The sintering time and temperatures have been reported to affect the final properties of the composites. SPS achieves superior sintering due to its unique nature and the versatile control over the processing variables, i.e., sintering time and temperature under the influence of the electric current and pressure, simultaneously. SPS is applied due to its distinctiveness, faster heating rates, lower sintering temperatures, and shorter sintering times. These features make SPS a favorable choice for the manufacture of AMCs. SPS yields AMCs with neartheoretical densification and fine grains, ultimately resulting in enhanced mechanical properties. ${ }^{23}$ In the work presented herein, an effort was made to combine powder metallurgy and SPS to process AlGNP composites with 0.1 wt. $\%, 0.5$ wt. $\%$, and 1 wt. $\%$ GNPs. Al6061 was used as a raw material due to its good formability and suitability for structural applications, being widely used in transport, building, marine, etc. fields. ${ }^{24}$

\section{MATERIALS, PROCESSING, AND CHARACTERIZATION}

Gas-atomized Al6061 powder (99.6\% purity) with spherical morphology (Fig. 1a) was used. A particle size of $\sim 20 \mu \mathrm{m}$ (Fig. 1c) was measured by a laser diffraction-based particle size analyzer (Mastersizer 3000; Malvern Instruments, UK). GNPs were purchased from Hongwu International, China, having average diameter of $8-12 \mu \mathrm{m}$ (Fig. 1b) and thickness $<10 \mathrm{~nm}$. Figure 1 shows SEM images of the raw materials.

The required weight quantity of GNPs was added to $70 \% / 30 \%$ water/ethanol solution, ${ }^{25}$ which was sonicated at frequency of $24 \mathrm{kHz}$ using a UP400S probe sonicator (Hielscher, Germany) for $1 \mathrm{~h}$. The corresponding amount of Al6061 powder (Table I) was added to the same solution and sonicated for 15 min. ${ }^{26}$ The composite Al-GNPs powders were then dried and subjected to ball milling at $200 \mathrm{rpm}$ for $2 \mathrm{~h}$ using a PM 400 planetary ball mill (Retsch $\mathrm{GmbH}$, Haan, Germany) with tungsten carbide balls (10:1 ratio).

The sonicated composite powders were then loaded into an SPS graphite die with inner diameter of $20 \mathrm{~mm}$. The composite powders were cold pressed at 3 tons in a Torin ${ }^{\circledR}$ Big Red $^{\mathrm{TM}} 10$ hydraulic press (model TY10003). The graphite die was then placed in an SPS 825 Dr Sinter unit (Fuji Electronic Industrial Co. Ltd., Japan) for SPSing at $450^{\circ} \mathrm{C}$ under vacuum and pressure of $60 \mathrm{MPa}$ with holding time of $10 \mathrm{~min}$. The Al-GNPs composites with all three loadings, i.e., $0.1 \mathrm{wt} . \%, 0.5 \mathrm{wt} . \%$, and $1 \mathrm{wt} . \%$, were prepared with fixed processing variables. Table I presents information on the reference and Al-GNP composites and their designated names as used in the present study. A schematic of the processing method applied to obtain the composites is shown in Fig. 1d. All the samples were subjected to solutionizing (Nabertherm P 330) by heating at $580^{\circ} \mathrm{C}$ for $30 \mathrm{~min}$ followed by quenching in water. Later, all the quenched samples were subjected to artificial ageing at $180^{\circ} \mathrm{C}$ for $8 \mathrm{~h}$.

The Archimedes principle was applied to measure the densities (Densitometer DahoMeter DH-300, DogGuan HongTuo Instruments Co. Ltd., China) of the SPS Al-GNPs composites, with accuracy of \pm $10^{-3} \mathrm{~g} / \mathrm{cm}^{3}$. For optical metallography, polished surfaces were achieved by grinding with emery papers of grit size 500, 800, 1200, and 2400 (Struers Silicon) at $100 \mathrm{rpm}$ to $200 \mathrm{rpm}$. The samples were later polished using alumina and diamond paste of $5 \mu \mathrm{m}, 3 \mu \mathrm{m}$, and $1 \mu \mathrm{m}$. To reveal the microstructure, etching was carried out by immersion for $30 \mathrm{~s}$ in Keller's reagent $(190 \mathrm{ml}$ distilled water with $3 \mathrm{ml}$ $\mathrm{HCl}, 5 \mathrm{ml} \mathrm{HNO}$, and $2 \mathrm{ml} \mathrm{HF}$ ) followed by washing in a stream of water. An optical microscope (Axio Scope A1, Carl-Zeiss-Straße, Germany) was then used, at magnifications up to $500 \times$.

Scanning electron microscopy (SEM, Supra 55VP; Zeiss) equipped with energy-dispersive spectroscopy (EDX, OCTANE PRO-A, EDAX, AMETEK Inc.) was used to examine the polished surfaces of the reference and composite samples. A Bruker D8 Advance DaVinci x-ray diffractometer was used for XRD analysis to determine the presence of phases resulting from SPS. For microstructure evaluation, electron backscattered diffraction (EBSD) analysis was used. The reference and composite samples for EBSD were subjected to ion beam milling using a Hitachi IM-3000 flat ion miller (Hitachi High-Technologies Corporation, Tokyo, Japan). A JEOL JEM 2010 was used at an accelerating voltage of $200 \mathrm{kV}$ for interfacial study of the Al-GNPs composites via transmission electron microscopy (TEM). 

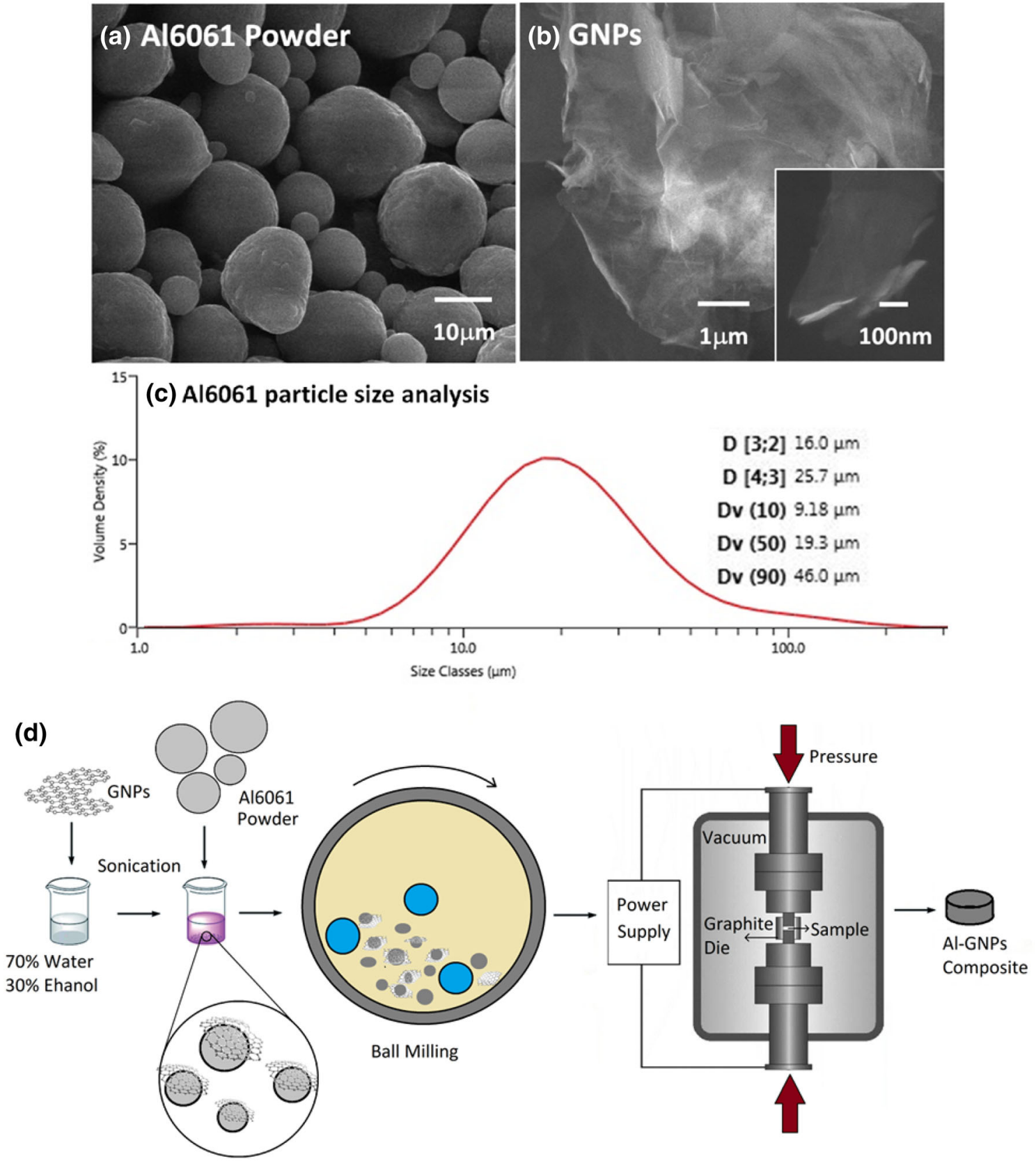

Fig. 1. SEM images of raw materials: (a) Al6061 powder and (b) GNPs, (c) particle size analysis of Al6061, and (d) schematic of processing steps

Micro Vickers hardness testing was carried out to determine the effect of the GNPs on the Al6061-T6 matrix. A Leica VMHT MOT (Leica Mikrosysteme, $\mathrm{GmbH}$ ) was used to measure the hardness by applying an indenter load of 50 gf for $10 \mathrm{~s}$. The mechanical behavior was determined by tensile testing performed on a Zwick/Roell Z2.5 (ZwickRoell GmbH \& Co. KG, Germany), equipped with a load cell with nominal force of $2.5 \mathrm{kN}$ (type Xforce HP, S/ $\mathrm{N} 764965$ ) at strain rate of $1 \mathrm{~mm} / \mathrm{min}$. The length $\times$ thickness $\times$ width dimensions of the tensile samples were $10 \mathrm{~mm} \times 1 \mathrm{~mm} \times 3 \mathrm{~mm}$ $( \pm 0.1 \mathrm{~mm} \times 0.02 \mathrm{~mm} \times 0.05 \mathrm{~mm})$.

\section{RESULTS AND DISCUSSION}

\section{Densities}

The theoretical densities were calculated by the rule of mixture as given by Eq. (1). ${ }^{27}$

$$
\rho_{\mathrm{c}}=\rho_{\mathrm{GNP}} V_{\mathrm{GNP}}+\rho_{\mathrm{M}} V_{\mathrm{M}}+\rho_{\mathrm{B} 4 \mathrm{C}} V_{\mathrm{B} 4 \mathrm{C}},
$$

where $\rho$ is the density and $V$ is the wt.\% in the matrix, and the subscripts "c," "GNP," and "M" indicate the composite, GNPs, and Al6061 matrix, respectively. The experimental densities of the reference and composites are presented in Table I. 
Table I. Description and properties of reference and Al-GNPs composites

\begin{tabular}{|c|c|c|c|c|c|c|c|c|}
\hline Sample & $\begin{array}{l}\text { Thermal } \\
\text { condition }\end{array}$ & Description & $\begin{array}{c}\text { Theoretical } \\
\text { density } \\
\left(\mathbf{g} / \mathbf{c m}^{\mathbf{3}}\right)\end{array}$ & $\begin{array}{l}\text { Experimental } \\
\text { density } \\
\left(\mathbf{g} / \mathbf{c m}^{\mathbf{3}}\right)\end{array}$ & $\begin{array}{c}\text { Grain } \\
\text { diameter } \\
(\mu \mathrm{m})\end{array}$ & $\begin{array}{c}\text { ASTM } \\
\text { grain } \\
\text { size } \\
(\#)\end{array}$ & $\begin{array}{l}\text { Hardness } \\
\text { (HV) }\end{array}$ & $\begin{array}{c}\text { Tensile } \\
\text { strength } \\
\text { (MPa) }\end{array}$ \\
\hline Al6061 & $\mathrm{T} 6$ & $\begin{array}{l}\text { Reference } \\
\text { sample }\end{array}$ & 2.7 & $2.7 \pm 0.0$ & $12.41 \pm 0.05$ & 9.37 & $72 \pm 2$ & $294 \pm 8$ \\
\hline $\begin{array}{l}\text { Al6061-0.1 } \\
\text { GNP-T6 }\end{array}$ & $\mathrm{T} 6$ & $\begin{array}{l}0.1 \text { wt. } \% \\
\text { GNPs }\end{array}$ & 2.699 & $2.695 \pm 0.001$ & $11.87 \pm 0.05$ & 9.5 & $80 \pm 2$ & $327 \pm 12$ \\
\hline $\begin{array}{l}\text { Al6061-0.5 } \\
\text { GNP-T6 }\end{array}$ & $\mathrm{T} 6$ & $\begin{array}{c}0.5 \text { wt. } \% \\
\text { GNPs }\end{array}$ & 2.694 & $2.693 \pm 0.001$ & $11.75 \pm 0.1$ & 9.53 & $88 \pm 3$ & $373 \pm 12$ \\
\hline $\begin{array}{l}\text { Al6061-1 } \\
\text { GNP-T6 }\end{array}$ & $\mathrm{T} 6$ & 1 wt. $\%$ GNPs & 2.688 & $2.685 \pm 0.002$ & $11.72 \pm 0.1$ & $9.54 \pm$ & $90 \pm 3$ & $287 \pm 15$ \\
\hline
\end{tabular}
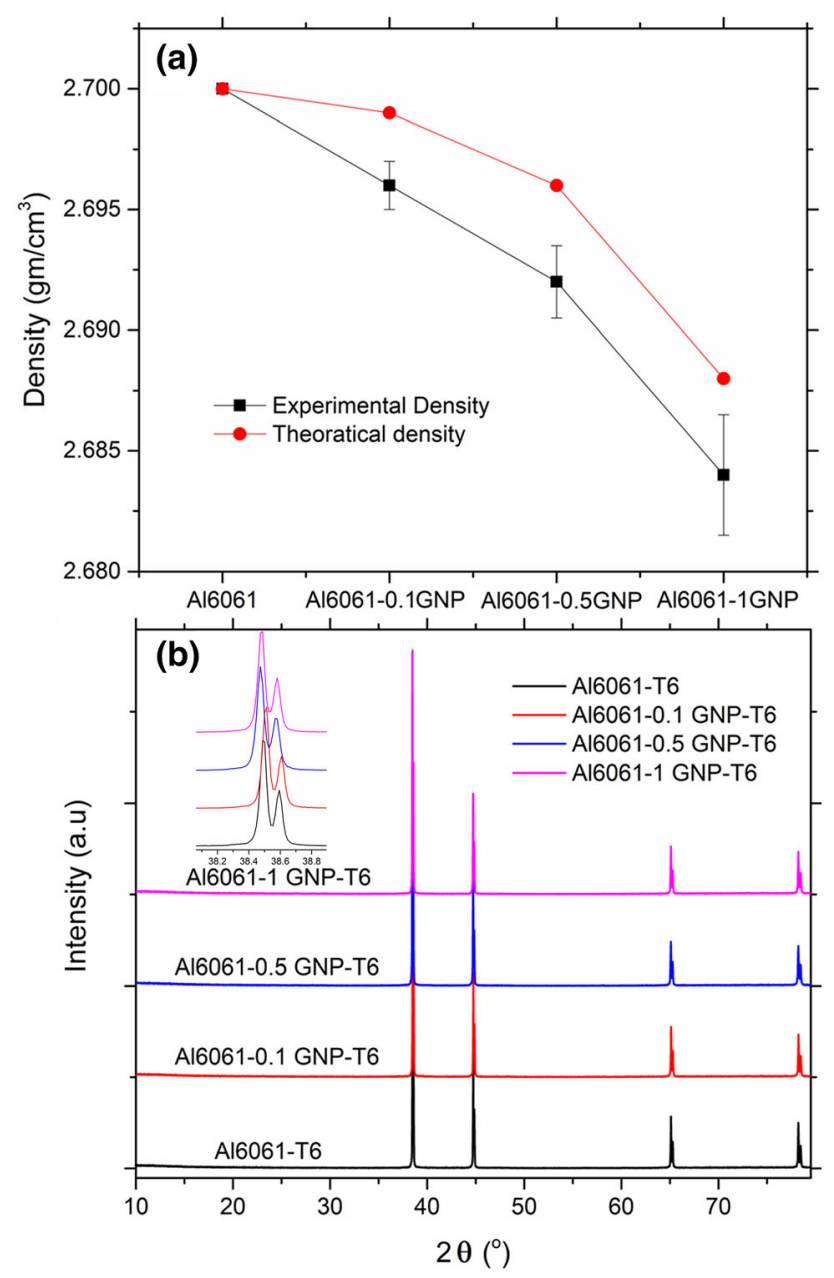

Fig. 2. Graphs showing; (a) theoretical and experimental densities of reference sample and Al-GNPs composites w.r.t GNP content and (b) XRD spectra of reference and Al-GNPs composites
Figure 2a shows the graphs of the theoretical and experimental densities plotted against the content of GNPs. Addition of GNPs lowered the density of the resulting composites as compared with the reference sample. The GNPs are lighter $(\sim 2 \mathrm{~g} /$ $\left.\mathrm{cm}^{3}\right)$ than the Al6061 matrix $\left(2.7 \mathrm{~g} / \mathrm{cm}^{3}\right)$, thus the reduction in the density of composites is greatly influenced by the processing method. ${ }^{28}$ The results of the present study agree with earlier work by Rashad et al. on pure aluminum with GNPs. ${ }^{29}$ The deviation of the experimental densities from the theoretical densities is related to the physical attachment of the GNPs to Al6061 grains. Generally, single-layer exfoliation of GNPs is impossible practically, resulting in the presence of a few layers at grain boundaries or interlocked between grains. These layered graphene structures are stacked over each other, with defects induced due to ball milling. These partially stacked and exfoliated GNPs result in the comparatively lower density of the composites compared with the theoretically achievable values.

\section{XRD Analysis}

Figure 2b shows the XRD patterns of the reference and Al-GNPs composites. Typical peaks pertaining to aluminum dominate the XRD spectra. The signal corresponding to the (111) plane with the maximum intensity remained the main contributor to the XRD patterns for all the reference as well as Al-GNPs composites. No peaks corresponding to GNPs appeared in the patterns of the Al-GNPs composites, ${ }^{30}$ mainly due to their low content, which is not detectable by the XRD instrument. Indeed, the detection limit of the XRD equipment results in a fundamental limitation ${ }^{31}$ of $\sim 3$ wt.\% of second phase/reinforcement. Moreover, peaks corresponding to $\mathrm{Al}_{2} \mathrm{O}_{3}$ or $\mathrm{Al}_{4} \mathrm{C}_{3}$ phases were not detected, indicating the absence of any phase or interphase at the $\mathrm{Al} / \mathrm{GNP}$ interfaces. ${ }^{32}$ SPS is superior to other processing techniques due to _ENREF_14its shorter 
exposure time at higher sintering temperatures, which is a reason for the restricted formation of $\mathrm{Al}_{4} \mathrm{C}_{3}$ in Al-GNPs composites. ${ }^{33}$ In contrast, formation of $\mathrm{Al}_{4} \mathrm{C}_{3}$ was reported by Yolshina et al. ${ }^{34}$ under the pressure and temperature with longer exposure time used in hot pressing. The inset in Fig. $2 \mathrm{~b}$ shows a shift of the XRD peaks corresponding to (111) planes to lower $2 \theta$ values. ${ }^{35}$ This shift indicates an increase in the $d$-spacing owing to the presence of stresses in the lattice planes. ${ }^{36}$ These stresses are induced due to the presence of GNPs in the $\mathrm{Al} 6061$ matrix in addition to $\mathrm{Mg}_{2} \mathrm{Si}$ precipitates (Fig. 4a).

\section{Microstructure Evolution}

Optical and SEM micrographs of the reference and $\mathrm{Al}-\mathrm{GNPs}$ composites are shown in Fig. 3. In general, the optical microstructures of all the SPS samples showed densification without any indication of processing-induced porosity. The microstructures shown in Fig. 3a, c, e, and g reveal a grain morphology consisting of deformed and distorted particles, in contrast to the raw Al6061 powder (Fig. 1a). The reason is the presintering consolidation and SPS of the reference and composite powders. The densification and distorted grain boundaries are relatable to the dual compaction of the raw Al6061 powder and ball-milled composite powders, which changed the spherical shape of the particles to a ball-milled morphology and finally to compressed sintered composites.

GNPs are optically transparent under light microscopy. ${ }^{13}$ The GNPs were trapped in the sintered Al6061 grains. ${ }^{37} \mathrm{~A}$ decrease in the grain size was observed with increasing content of GNPs (Fig. 3b) in comparison with the microstructure of the reference sample (Fig. 3a). This observation is in accordance with the results of Saboori et al. ${ }^{18}$ Entrapped GNPs wrap around the grains and tend to hold them together by interlocking and anchoring after sintering. Lumps or agglomerates of GNPs were not found by optical microscopy at the mentioned magnification (Fig. 3c, e, and g). This observation can be attributed to the uniform distribution of the GNPs after ball milling with the selected parameters. Thicker grain boundaries can be seen in the microstructure of the Al6061-1 GNP-T6 composite (Fig. 3g), indicating the higher content of GNPs.

Secondary-electron SEM images of the polished unetched Al6061 reference samples in T6 state (Fig. 3b) and Al-GNPs composites are shown in Fig. 3d, f, and h. No evidence of significant porosity can be seen, owing to the good compaction and subsequent SPS sintering. Unetched samples revealed no grain boundaries, thus tracing of lumps or agglomerates became possible. An almost planepolished surface of the Al6061 matrix can be predominantly seen in Fig. $3 \mathrm{~b}$, $\mathrm{d}$ for the reference and Al6061-0.1GNP composite. Scarcely any clustered GNPs could be seen in the Al60610.5GNP composite (Fig. 3e, f). These GNPs are mechanically interlocked and surrounded by Al6061 matrix grains. Addition of 1 wt. \% GNPs resulted in many uniformly distributed lumps of GNPs (Fig. 3h).

Figure 4 shows TEM images of the reference and Al6061-1 GNP-T6 composite. Entrapped and anchored GNPs are present at the grain boundaries. A clean interphase-free aluminum/GNP interface can be seen in Fig. 4b, without any nanoparticles or precipitates. This evidence strengthens the XRD results. A strong mechanical interface indicates better load transfer capabilities during mechanical testing ${ }^{32}$.

\section{EBSD}

EBSD is a powerful tool for microstructural analysis ${ }^{38}$ ] providing data on grain crystallographic orientations, morphology, and grain boundaries. ${ }^{39}$. Figure 5 shows the inverse pole figures (IPFs) of the Al-GNPs composites. Addition of GNPs to the Al6061 resulted in a grain size reduction from $12.4 \mu \mathrm{m}$ to $\sim 11.7 \mu \mathrm{m}$. The EBSD results of the present study are in accordance with our earlier findings based on optical microscopy of Al6061 with the same raw material. ${ }^{34}$ Randomly distributed black spots can be seen in the IPF images in Fig. 5b, c, and $\mathrm{d}$. These unindexed points can be related to fractional deviation of the pattern matching at or near grain boundaries (or due to the presence of GNPs). The average decrease in grain size is $\sim 5 \%$ (Table I).

Figure 6a shows the grain diameter $(\mu \mathrm{m})$ and corresponding ASTM grain size number plotted against the content of GNPs in the Al6061 matrix. Potential areas suspected to be GNPs at the grain boundaries are marked with circles in Fig. 5b, c, and $d$. Addition of GNPs resulted in a decrease in the grain size of the Al6061 matrix. The grains were partially surrounded by GNPs. Thus, sintering was restricted at the edges covered by GNPs (Fig. 5b), causing comparatively lesser grain growth than in the monolithic Al6061-T6 matrix (Fig. 5a). Further addition of GNPs to 0.5 wt.\% (Fig. 5c) resulted in a more uniform distribution across the matrix grains, causing a decrease in the grain size as seen in Fig. 6a. At 1 wt.\% GNPs (Fig. 5d), the minimum grain size was observed due to the maximum dispersion and clustering in the Al6061 matrix. Saturation of GNPs surrounding the maximum Al6061 matrix grains is seen in Fig. 6a. This trend for saturation can be associated with the distribution of GNPs as controlled by the selected ball milling parameters. In other words, addition of 1 wt.\% GNPs could be the limit beyond which further dispersion of GNPs and achievement of improved properties in the Al6061 matrix is not possible. 


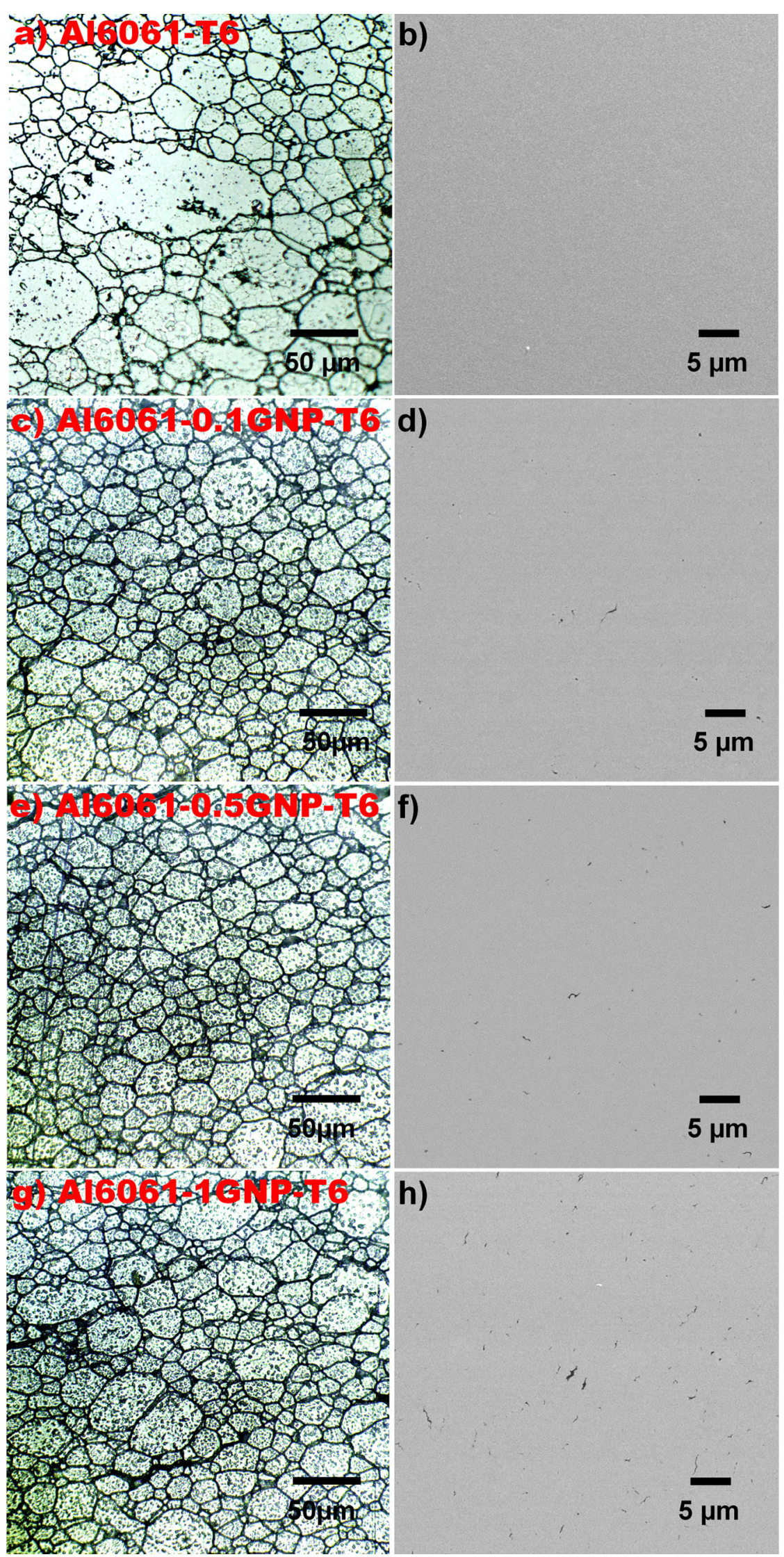

Fig. 3. Microstructures: (a) optical and (b) SEM images of reference T6 sample, (c) optical and (d) SEM images of Al6061-0.1 GNP-T6, (e) optical and (f) SEM images of Al6061-0.5 GNP-T6, and (g) optical and (h) SEM images of Al6061-1 GNP-T6 composite 

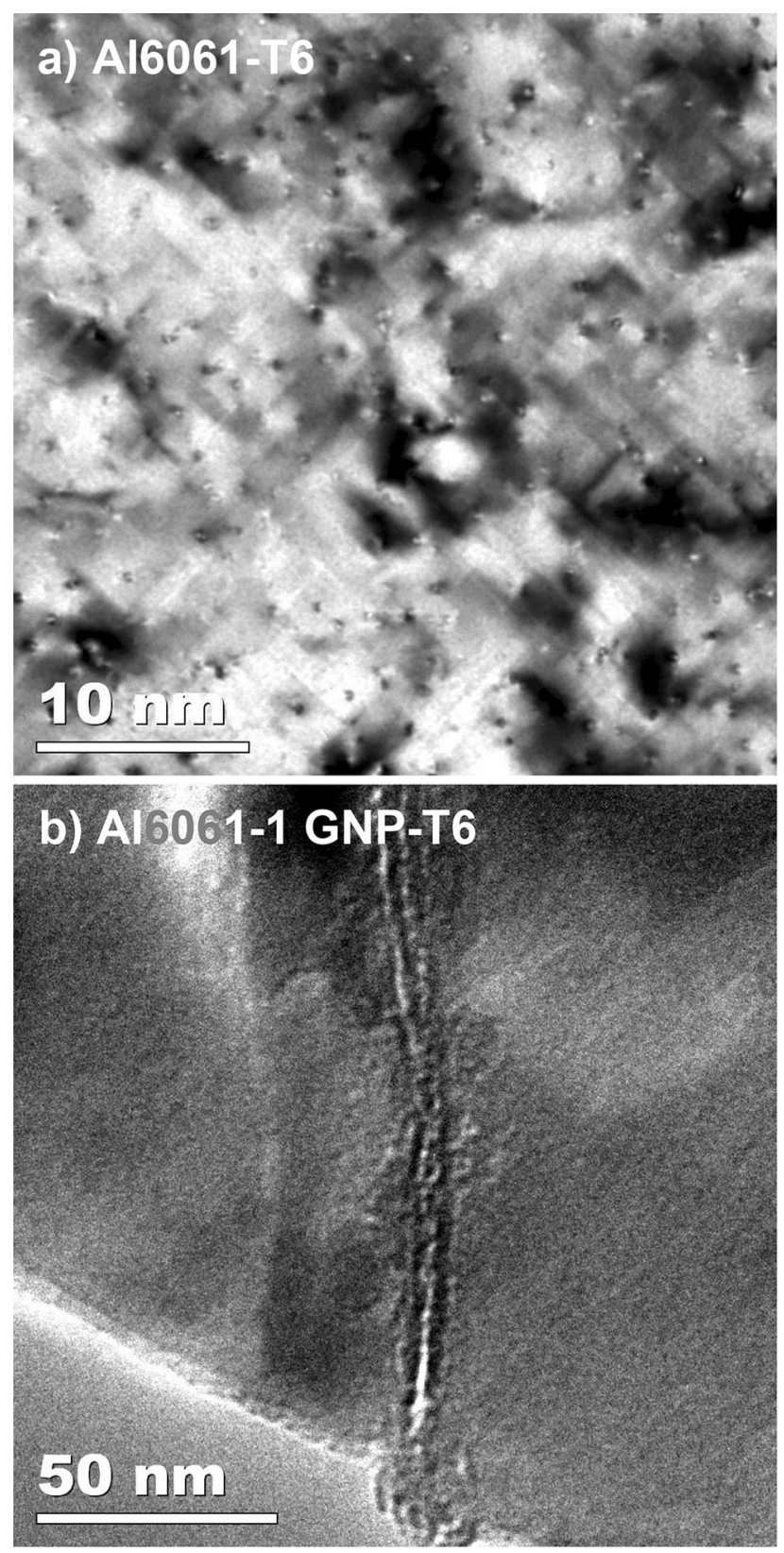

Fig. 4. TEM images of (a) $\mathrm{Mg}_{2} \mathrm{Si}$ precipitate in Al6061-T6 matrix and (b) GNPs entrapped between two grains in Al6061-1 GNP-T6 composite sample

\section{Hardness}

The hardness values of the reference T6 samples and Al-GNPs composites are plotted in Fig. $6 \mathrm{~b}$ and presented in Table I. The reference Al6061-T6 sample showed a hardness value of $72 \pm 2 \mathrm{HV}$, which increased to $80 \pm 2 \mathrm{HV}$ when adding 0.1 wt.\% GNPs. Further addition of GNPs to 0.5 wt. $\%$ and 1 wt.\% increased the hardness to $88 \pm 3 \mathrm{HV}$ and $90 \pm 3 \mathrm{HV}$, demonstrating a rise of $17 \%$ and $19 \%$, respectively. A similar trend of increasing hardness with addition of GNPs was reported by Latief et al. $^{40}$ in pure aluminum.

According to the Hall-Petch relationship, the reduction in grain size observed in the EBSD analysis will result in an increase in the hardness. A higher number of grain boundaries per unit length indicates a higher number of dislocations. The grain growth is also associated with the sintering temperature and time, as reported by Bisht et al., ${ }^{41}$ thus controlling the sintering time can restrict the grain growth and eventually increase the hardness of the Al6061 matrix as observed. The absence of the intermetallic phase $\mathrm{Al}_{4} \mathrm{C}_{3}$ is another reason for the increase in hardness, as reported by Bartolucci et al. ${ }^{42}$ and Khan et al. ${ }^{43}$

\section{Tensile Testing}

Figure $6 \mathrm{c}$ shows the stress-strain curves of the reference and Al-GNPs composites in $\mathrm{T} 6$ condition. An increase in the yield point and ultimate tensile strength can be seen at the cost of a reduction in ductility. The baseline data of the $\mathrm{T} 6$ reference sample show strength, tensile strength, and failure strain values of $189 \pm 4 \mathrm{MPa}, 294 \pm 3 \mathrm{MPa}$, and $12 \pm 1.5 \%$, respectively. An increase of up to $60 \%$ and $11 \%$ in the yield and ultimate tensile strength were observed for the Al6061-0.1GNP-T6 composites, while the ductility responded adversely with a decrease of $50 \%$ (Fig. 6b). Further addition of GNPs up to 0.5 wt.\% in the Al6061 matrix yielded increases of $80 \%$ and $27 \%$ in the yield and tensile strength. A drastic decrease in the failure strain was observed $(\sim 67 \%)$. The minimum improvement in the yield and ultimate tensile strength was recorded for the Al6061-1GNPs-T6 sample, viz. $13 \%$ and $-2.5 \%$ compared with the Al6061-T6 reference standard. The ductility almost diminished to $2 \%$ of the failure strain.

The contribution of the GNPs at grain boundaries was seen in the XRD pattern as a shift of the typical crystallographic peaks due to stresses. The effect of these lattice strains remained inactive until the stress reached the level of hindrance within the crystal lattice due to $\mathrm{Mg}_{2} \mathrm{Si}$ precipitates (Fig. 4a). The dislocation density increased with a grain size reduction due to the presence of GNPs at grain boundaries. A higher amount of stress is required to overcome this strain hardening effect. When increasing the content of GNPs to 0.5 wt.\%, higher yield and ultimate tensile strength were recorded for this composite. The strain hardening effect can be seen in the stress-strain curves. Because of the higher stress that must be applied to overcome the accumulated strain in the lattices and dislocation pile-up, the plasticity of the composite was compromised. Therefore, higher strength and minimal plasticity are exhibited. The failure of the Al60611 GNP-T6 composite at lower stress was dominated by the presence of evenly distributed lumps of GNPs in the Al6061 matrix (Fig. 5d). These clusters of 

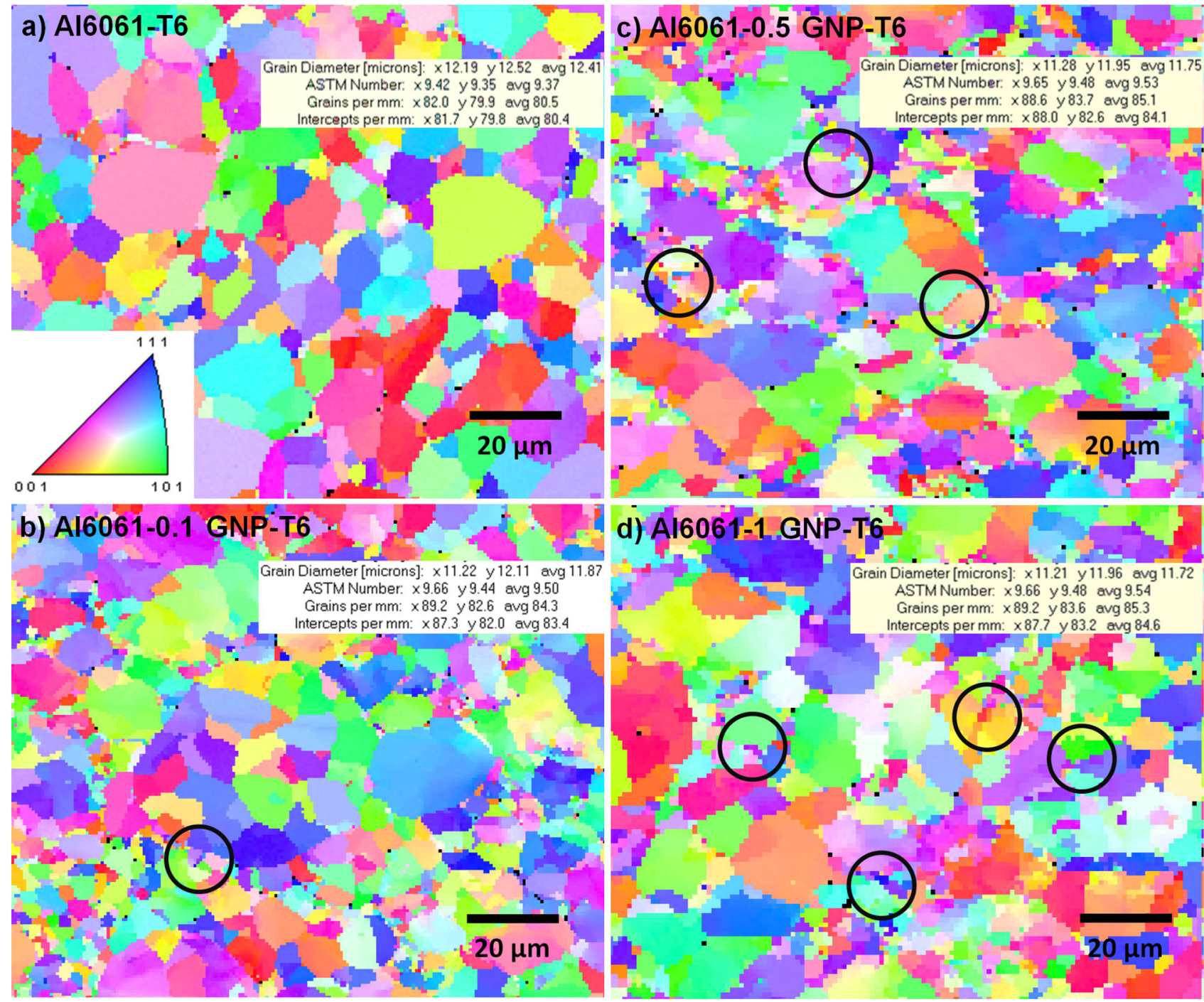

Fig. 5. EBSD IPFs with grain data of (a) reference T6 sample and (b) Al6061-0.1 GNP-T6, (c) Al6061-0.5 GNP-T6, and (d) Al6061-0.1 GNP-T6 composites

GNPs act as stress concentration areas, leading to crack propagation.

\section{CONCLUSIONS}

The following conclusions can be drawn from the present study in light of employed processing and characterization techniques:

1. A uniform dispersion of GNPs was obtained at the selected ball milling parameters.

2. Near-theoretical densities of the reference and Al-GNPs composites were achieved after optimization of SPS parameters.

3. GNPs affected the microstructure by causing grain refinement and anchoring between Al6061 matrix grains.

4. Varying the content of GNPs improved the grain refinement by spreading across grain bound- aries and interacting with dislocations, resulting in an enhancement of the mechanical properties.

5. The XRD patterns showed typical aluminum peaks with the absence of any potential interphase at Al6061/GNPs interfaces. The TEM results complemented the XRD data by revealing neat and clean interfaces.

6. The observed increase in the hardness and tensile strength can be related to the HallPetch effect dominated by the grain refinement and anchoring contribution of the GNPs. Al6061-0.1GNP-T6 showed the maximum tensile strength, whereas the composite with 1 wt.\% GNPs failed prematurely owing to the presence of evenly distributed GNP lumps which acted as crack initiation points. 
(a)
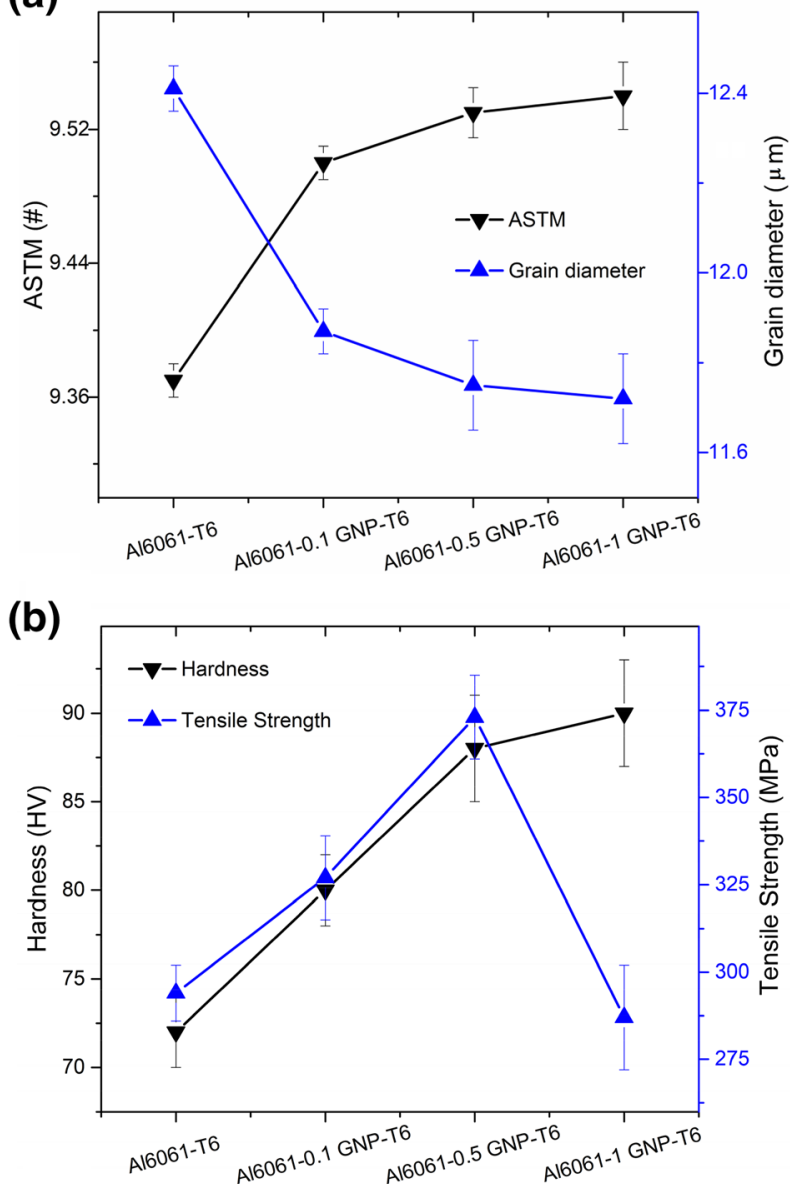

(c)

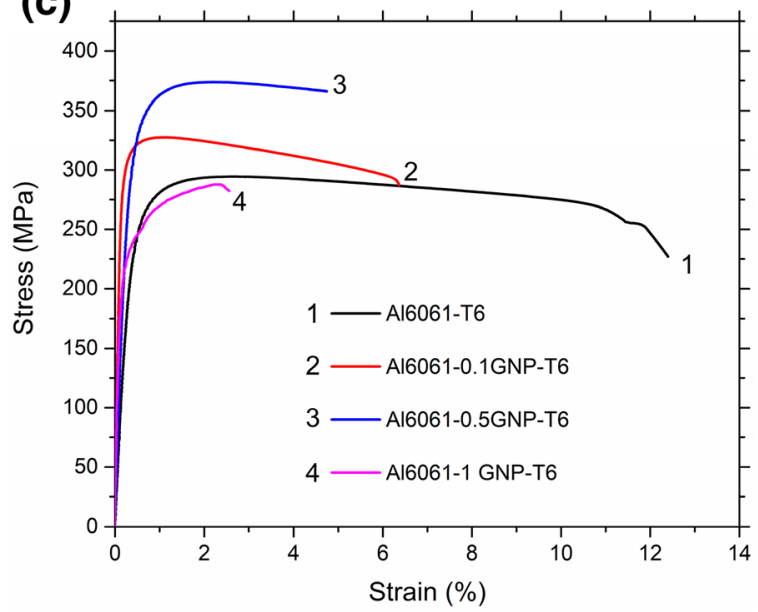

Fig. 6. Variation of (a) ASTM number and grain diameter from EBSD data, (b) Vickers hardness and tensile strength, and (c) stress-strain behavior of Al6061 matrix in T6 matrix versus GMP content

\section{ACKNOWLEDGEMENTS}

Open Access funding provided by NTNU Norwegian University of Science and Technology (incl St. Olavs Hospital - Trondheim University Hospital). The authors acknowledge the financial support from the Higher Education Commission of Pakistan
(Grant No. 213-53249-2EG2-102) provided under the $\mathrm{PhD}$ indigenous fellowship; Phase-II Batch-II and Norwegian University of Science and Technology (NTNU), Norway for use of their laboratory facilities for characterization of all material properties.

\section{OPEN ACCESS}

This article is licensed under a Creative Commons Attribution 4.0 International License, which permits use, sharing, adaptation, distribution and reproduction in any medium or format, as long as you give appropriate credit to the original author(s) and the source, provide a link to the Creative Commons licence, and indicate if changes were made. The images or other third party material in this article are included in the article's Creative Commons licence, unless indicated otherwise in a credit line to the material. If material is not included in the article's Creative Commons licence and your intended use is not permitted by statutory regulation or exceeds the permitted use, you will need to obtain permission directly from the copyright holder. To view a copy of this licence, visit http://creativecommons.org/licenses/by/4.0/.

\section{REFERENCES}

1. M. Khan, A. Rehman, T. Aziz, K. Naveed, I. Ahmad, and T. Subhani, Mater. Sci. Eng. A 696, 552 (2017).

2. D.B. Miracle, Compos. Sci. Technol. 65, 2526 (2005).

3. M. Khan, A. Rehman, T. Aziz, M. Shahzad, K. Naveed, and T. Subhani, J. Mater. Process. Technol. 253, 72 (2018).

4. K. Ravikumar, K. Kiran, and V.S. Sreebalaji, Measurement 102, 142 (2017).

5. C.-H. Jeon, Y.-H. Jeong, J.-J. Seo, H.N. Tien, S.-T. Hong, Y.J. Yum, S.-H. Hur, and K.-J. Lee, Int. J. Precision Eng. Manuf. 15, 1235 (2014).

6. S.E. Shin and D.H. Bae, Compos. Part A 78, 42 (2015).

7. A.K. Geim and K.S. Novoselov, Nanoscience and Technology: A Collection of Reviews from Nature Journals (Singapore: World Scientific, 2010), pp. 11-19.

8. M. Hedayatian, A. Momeni, A. Nezamabadi, and K. Vahedi, Compos. Part B 182, 107652 (2020).

9. W. Zhou, Y. Fan, X. Feng, K. Kikuchi, N. Nomura, and A. Kawasaki, Compos. Part A 112, 168 (2018).

10. Z. Li, Q. Guo, Z. Li, G. Fan, D.-B. Xiong, Y. Su, J. Zhang, and D. Zhang, Nano Lett. 15, 8077 (2015).

11. S. Wang, X. Wei, J. Xu, J. Hong, X. Song, C. Yu, J. Chen, X. Chen, and H. Lu, Mater. Des. 186, 108212 (2020).

12. R. Pérez-Bustamante, D. Bolaños-Morales, J. Bonilla-Martínez, I. Estrada-Guel, and R. Martínez-Sánchez, J. Alloys Compd. 615, S578 (2014).

13. M. Khan, M. Amjad, A. Khan, R. Ud-Din, I. Ahmad, and T. Subhani, J. Mater. Res. 1 (2017).

14. A. Bisht, M. Srivastava, R.M. Kumar, I. Lahiri, and D. Lahiri, Mater Sci Eng A 695, 20 (2017).

15. W. Yang, Q. Zhao, L. Xin, J. Qiao, J. Zou, P. Shao, Z. Yu, Q. Zhang, and G. Wu, J. Alloys Compd. 732, 748 (2018).

16. H.G. Prashantha Kumar, M. Anthony Xavior, A.P. Joel, and J. Kaustav Chakraborty, Mater. Today: Proc. 5, 6626 (2018).

17. M. Khan, W.H. Syed, S. Akhtar, and R.E. Aune, Friction Stir Welding and Processing $X$ (Springer International: Cham, 2019), pp. 217-232.

18. A. Saboori, M. Pavese, C. Badini, and P. Fino, Acta Metall. Sin. (Engl. Lett.) 30, 675 (2017).

19. M. Khan, R. Ud-Din, W.H. Syed, and S. Akhtar, R.E. Aune.2019 16th International Bhurban Conference on Ap- 
plied Sciences and Technology (IBCAST), ed. D.M. ZafarUz-Zaman (Islamabad, Pakistan: IEEE, 2019), pp. 35-41.

20. J. Wang, Z. Li, G. Fan, H. Pan, Z. Chen, and D. Zhang, Scr. Mater. 66, 594 (2012).

21. S.A. Sajjadi, M. Torabi Parizi, H.R. Ezatpour, and A. Sedghi, J. Alloys Compd. 511, 226 (2012).

22. M. Rahimian, N. Ehsani, N. Parvin, and H.R. Baharvandi, J. Mater. Process. Technol. 209, 5387 (2009).

23. R. Orrù, R. Licheri, A.M. Locci, A. Cincotti, and G. Cao, Mater. Sci. Eng. R 63, 127 (2009).

24. J. Hirsch, B. Skrotzki, and G. Gottstein, Aluminium Alloys: The Physical and Mechanical Properties (Hoboken: Wiley, 2008).

25. W.-W. Liu, B.-Y. Xia, X.-X. Wang, and J.-N. Wang, Front. Mater. Sci. 6, 176 (2012).

26. J.-M. Ju, G. Wang, and K.-H. Sim, J. Alloys Compd. 704, 585 (2017).

27. N. Chawla and K.K. Chawla, Metal Matrix Composites (New York: Springer, 2013).

28. M. Ipekoglu, A. Nekouyan, O. Albayrak, and S. Altintas, J. Mater. Res. 32, 599 (2017).

29. M. Rashad, F. Pan, A. Tang, and M. Asif, Prog. Nat. Sci.: Mater. Int. 24, 101 (2014).

30. W.M. Tian, S.M. Li, B. Wang, X. Chen, J.H. Liu, and M. Yu, Int. J. Miner. Metall. Mater. 23, 723 (2016).

31. M. Bastwros, G.-Y. Kim, C. Zhu, K. Zhang, S. Wang, X. Tang, and X. Wang, Compos. Part B 60, 111 (2014).

32. A. Bhadauria, L.K. Singh, and T. Laha, Mater. Sci. Eng. A 749,14 (2019).
33. M. Khan, M. Zulfaqar, F. Ali, and T. Subhani, Mater. Sci. Technol. 33, 1955 (2017).

34. L.A. Yolshina, R.V. Muradymov, I.V. Korsun, G.A. Yakovlev, and S.V. Smirnov, J. Alloys Compd. 663, 449 (2016).

35. A.L. Ortiz and L. Shaw, Acta Mater. 52, 2185 (2004).

36. P.S. Prevey and ASM International, ASM Handbook 10, 380 (1986).

37. M. Khan, R. Din, A. Wadood, W.H. Syed, S. Akhtar, and R.E. Aune, J. Alloys Compd. 790, 1076 (2019).

38. A.J. Schwartz, M. Kumar, B.L. Adams, and D.P. Field, Electron Backscatter Diffraction in Materials Science (New York: Springer, 2000).

39. J. Guo, S. Amira, P. Gougeon, and X.G. Chen, Mater. Charact. 62, 865 (2011).

40. F.H. Latief, E.-S.M. Sherif, A.A. Almajid, and H. Junaedi, J. Anal. Appl. Pyrolysis 92, 485 (2011).

41. A. Bisht, V. Kumar, L.H. Li, Y. Chen, A. Agarwal, and D. Lahiri, Mater. Sci. Eng. A 710, 366 (2018).

42. S.F. Bartolucci, J. Paras, M.A. Rafiee, J. Rafiee, S. Lee, D. Kapoor, and N. Koratkar, Mater. Sci. Eng. A 528, 7933 (2011).

43. M. Khan, M. Zulfaqar, F. Ali, and T. Subhani, Met. Mater. Int. (Seoul, Repub. Korea) 23, 813 (2017).

Publisher's Note Springer Nature remains neutral with regard to jurisdictional claims in published maps and institutional affiliations. 